\title{
Efficiency, Technical Progress, and Best Practice in Chinese State Enterprises (1980-1994)
}

\author{
by \\ Jinghai Zheng, Xiaxuan Liu ${ }^{1}$ and Arne Bigsten
Working Papers in Economics no 30
September, 2000
Department of Economics
Göteborg University

\begin{abstract}
In spite of rapid economic growth and swift structural change during the last two decades, China's industrial reform is far from complete, especially with regard to state enterprises (SOEs). Although troubled with huge financial losses, heavy debt, and substantial over-staffing, SOEs will continue to play a crucial part in the government policy to maintain social stability and economic growth in China. This study, based on samples of about 700 state enterprises during 1980-94, investigates productivity performance of the SOEs using Data Envelopment Analysis and Malmquist Index. Our empirical results show that average technical efficiency had been low among the sample SOEs. Considerable productivity growth was found, but it was mainly accomplished through technical progress rather than efficiency improvement. Regression analyses indicate that wage incentives and education had positive impacts on productivity growth, while large scale was an important determinant of whether an SOE was applying best practice technology. It is also shown that large SOEs were more likely to generate technical progress. These findings are consistent with the industrial structural adjustment program initiated by the government in 1994, which has focused on improving productive efficiency via redundancies and technology upgrading, and on building its best SOEs into conglomerates.
\end{abstract}

Keywords: Efficiency, productivity, technical progress, state enterprises, reform

JEL-classification: D2, P2

Department of Economics

Scholl of Economics and Commercial Law

Göteborg University

P.O. Box 640

SE 40530 Göteborg, Sweden

Tel: $+46-31-7734139$ and 7731358

Fax: +46-31-7731326

E-mail: Jinghai.Zheng@economics.gu.se and Arne.Bigsten@economics.gu.se

\footnotetext{
${ }^{1}$ Institute of Economics, Chinese Academy of Social Sciences, Beijing 100836, P. R. China
} 


\section{Introduction}

Since economic reforms were initiated in the late 1970s, an important feature of China's economic growth is its reliance on productivity growth. In recent years, in order to further boost productivity and sustain economic growth, China's State Planning Commission issued a set of general guidelines for restructuring the economy and accelerating development of key industries. These guidelines emphasize the importance of promoting large state enterprises (SOEs) and enterprise groups, and improving productive efficiency via redundancies and technology upgrading.

Contrary to what has been commonly perceived, some recent studies argue that China's large SOEs are not stagnant fossils waiting to die. Under economic reform policies this sector has undergone large change due to enhanced enterprise autonomy, the impact of market forces, rapid growth of domestic demand for upstream products, strategic integration with the world economy and the state's policy to promote large businesses (Nolan and Wang, 1999). In conjunction with the non-state sector, large-scale enterprises have been an important engine for growth over an extended period in China (Smyth, 2000). These studies present a challenge to the "transitional orthodoxy," namely that only privatization can solve the industrial problems of communist countries. At the center of this debate, is the issue of the productivity performance of SOEs, especially large SOEs. However, due to the lack of empirical studies in the literature, this issue deserves further investigations using comprehensive enterprise level data.

A number of empirical studies have attempted to measure the total factor productivity (TFP) growth for the Chinese state-owned sector as a whole. Although some have found that economic reform has made little or no contribution to TFP growth in the state sector, most have found that TFP growth in SOEs has improved since 1978, while lagging behind the township and village enterprises (Smyth, 2000). However, there are few studies, which distinguish large-scale SOEs from SOEs as a whole. Lo (1999) is the only study that explicitly compares TFP growth in large and medium state enterprises (LMEs), SOEs as a whole, and collective enterprises (COEs). He estimates a Cobb-Douglas production function using aggregate data for 1980-95. One important finding in his study is that in terms of productivity growth COEs performed better than both SOEs and LMEs, but LMEs performed much better than SOEs as a whole. In this paper, as a further effort to the study on the performance of SOEs, we investigate the productivity characteristics of best practice SOEs with special emphasis on large enterprises.

Most previous productivity studies of the SOE sector have been concentrating on 
average productivity growth and a considerable portion of the literature has used conventional methodologies such as Cobb-Douglas production function estimations. Although studies using modern approaches including stochastic and deterministic frontier production function estimations have been increasing, none of the studies has focused on best practice SOEs. An investigation of best practice SOEs, especially the identification and characterization of those with substantial efficiency improvement and technical progress, will improve understanding of the determinants of productivity growth in the state industrial sector, and on the perspective of forming large enterprise groups (conglomerates) with the best practice SOEs at the core.

On the basis of a panel data from about 700 state enterprises for the period 1980-94, this study uses Data Envelopment Analysis (DEA) and the Malmquist index to evaluate productivity performance of SOEs. Total factor productivity (TFP) growth is decomposed into efficiency improvement and technical progress. Production frontiers are estimated for each of the two-digit industries in our sample using disaggregated employment and material data. The best practice SOEs are thus identified. With these methodologies, the determinants of best practice SOEs and productivity growth are analyzed by using regression techniques for limited dependent variable models with random effects. The plan of the paper is as follows. In Section 2, we present the background of our study. In Section 3, we briefly discuss previous studies in the literature, and introduce the methodologies used in this study. Data is presented in Section 4. Section 5 reports and analyzes empirical results, and Section 6 concludes the study.

\section{Background}

In spite of rapid economic growth and swift structural change during the last two decades, China's industrial reform is far from complete, especially with regard to SOEs. For the time being, SOEs are still of great importance in terms of urban employment and total investment in industrial fixed assets, while their share of industrial output has been steadily declining. ${ }^{1}$ In the foreseeable future, state enterprises will continue to be replaced by nonstate firms in terms of employment creation, given the recent government policy to "grasp the large, release the small." "2 Although most SOEs have been troubled with huge financial losses, heavy debts, and substantial over-staffing, it is the government's ambition that state enterprises shall play a crucial part in maintaining social stability and sustained economic growth in China. In order to revitalise the state industrial sector, the structural adjustment program initiated by the government in 1994 has focused on improving productive efficiency 
via redundancies and technology upgrading, and on building its best SOEs into conglomerates (the establishment of the modern enterprise system). ${ }^{3}$

Among Chinese economists, industrial policy has long been a topic for controversy. Those who oppose such policies suggest that state ownership should be eliminated from all areas of industrial production but a few sectors such as transportation and telecommunication. After the breakout of South East Asia financial crisis, more doubts have been cast on the appropriateness of developing Japanese and South Korean style conglomerates in China. For ideological reasons, among other things, the government is in favour of state ownership at least in some major industrial sectors. Recent changes in the international political environment (e.g., Kosovo crisis) and China's forthcoming entry into the World Trade Organisation have intensified the debate among Chinese economists and policy analysts on the role of state enterprises in the context of sustainable growth, economic security, and political stability (e.g., Wang, 2000).

The unsatisfactory financial performance of most SOEs is not really an issue in dispute. Some economists argue, however, that thanks to the management reforms carried out since the late 1970s and early 1980s the fundamentals of some SOEs have been improved with respect to efficiency and technology. The increasing losses in SOEs since the early 1990s were, in their view, mainly due to the unfavorable external environment such as intense and sometimes "unfair" competitions from township and village enterprises, and joint ventures. Heavy social responsibilities (e.g., pension, housing, and over-staffing) were also blamed for their poor performance (Lin and Tan, 1999). It is thus not difficult to understand the recent focus of the government's structural adjustment program on the introduction of the modern enterprise system, reduction of over-staffing, and technology upgrading. These measures have been accompanied by housing, pension, and other welfare reforms, which were expected to reduce enterprise burdens. The emphasis on the modern enterprise system reflects the long-standing view of some economists that SOEs are basically reformable if effective management methods can be implemented, while reduction of over-staffing and technology upgrading were directly aiming at boosting productivity growth in SOEs.

In this study, we take up two issues concerning the productivity performance of SOEs during the period of economic reforms: improvement in technical efficiency and technical progress in SOEs in general, and the behavior of best practice SOEs in particular. Improvement in technical efficiency is one of the fundamental aspects of Chinese enterprise reforms, because various incentive schemes intended to improve management efficiency have been introduced or experimented with at various stages of the reform process since the late 
1970s. An empirical evaluation would provide evidence as to the effectiveness of management reforms in SOEs. Since the early stage of the enterprise reform, tremendous efforts have been made to upgrade technologies of SOEs. Considerable investments in relatively advanced technologies from Western countries took place in forms of direct purchases, technology transfers, and joint ventures. Whether SOEs are to maintain their status as engines of economic growth into the 21 st century, depends to a large extent on their ability to adapt new technologies. However, the situation in terms of technical progress may differ from one SOE to the other, given their diverse performance. A closer look at the best practice SOEs, especially those with substantial technical progress, may shed some light on the determinants of productivity growth in the state industrial sector, and on the perspective of forming conglomerates with the best practice SOEs as the core.

\section{Methodology}

In comparison with productivity studies using aggregate time series data, there have been fewer such studies in which enterprise level data are used. ${ }^{4}$ Productivity outcomes depend on many factors. Trends in total factor productivity (TFP) reflect the efficacy of reform policy, enterprise response to changes in competition and other aspects of market structure, learning effects, and the benefits of new equipment, technical know-how, and organizational skills, as well as the impact of social, political, or institutional obstacles to potentially fruitful innovations. It is thus difficult to ascertain the cause of productivity movements since changes in aggregate productivity conceal a rich variety of microeconomic behavior (Jefferson et. al, 1996). Therefore, there is a need for more productivity studies at lower levels of aggregation for selected industries, in which higher rate of efficiency improvement and technical progress are expected.

Although most studies on Chinese productivity have used the traditional method of average production function estimations, studies using modern approaches such as stochastic and deterministic frontier production function estimations have been increasing. For instance, Lau and Brada (1990) estimated a parametric deterministic frontier production function using aggregate industrial time series data from 1953-1985; Zheng, Liu, and Bigsten (1998) compared the difference in technical efficiency between state-owned enterprises and township-village enterprises by conducting data envelopment analysis (DEA) for the period 1986-90; a comparative static DEA model (the Malmquist index method) was applied to Chinese state enterprise data from 1980, 1984, and 1985 in Färe et. al (1996); Liu and Zheng (1998) studied determinants of technical efficiency in Chinese state enterprises during 1985- 
1994 by using a two-step procedure in the estimation of stochastic production frontiers; and $\mathrm{Wu}$ (1995) employed a stochastic frontier panel data model proposed by Cornwell et al. (1990) to examine total factor productivity growth, technological progress, and technical efficiency change using Chinese provincial data for 1985-1991.

In this study, we are interested in searching for micro evidence as to whether there had been TFP growths at a well-defined industrial level in the state sector, by employing a DEA-based Malmquist index method, which has not often been used on Chinese data. The Malmquist index is a type of quantity indexes constructed as ratios of distance functions (Caves et al. 1982a and 1982b). Since distance functions are not accessible to the general reader in terms of notation, we adopt here a notation system based on technical efficiency measures defined in Førsund and Hjalmarsson (1979).

In Figure 1, x stands for input and y for output. Assuming that one has input and output data for two years, points $\left(\mathrm{x}^{1}, \mathrm{y}^{1}\right)$ and $\left(\mathrm{x}^{2}, \mathrm{y}^{2}\right)$ are observations from year 1 and year 2 . Two production frontiers with constant returns to scale (CRS) are drawn as lines 01 for the first year and 02 for the second year. The first year's frontier is constructed using the first year's input and output observations and the second year's frontier using the second year's

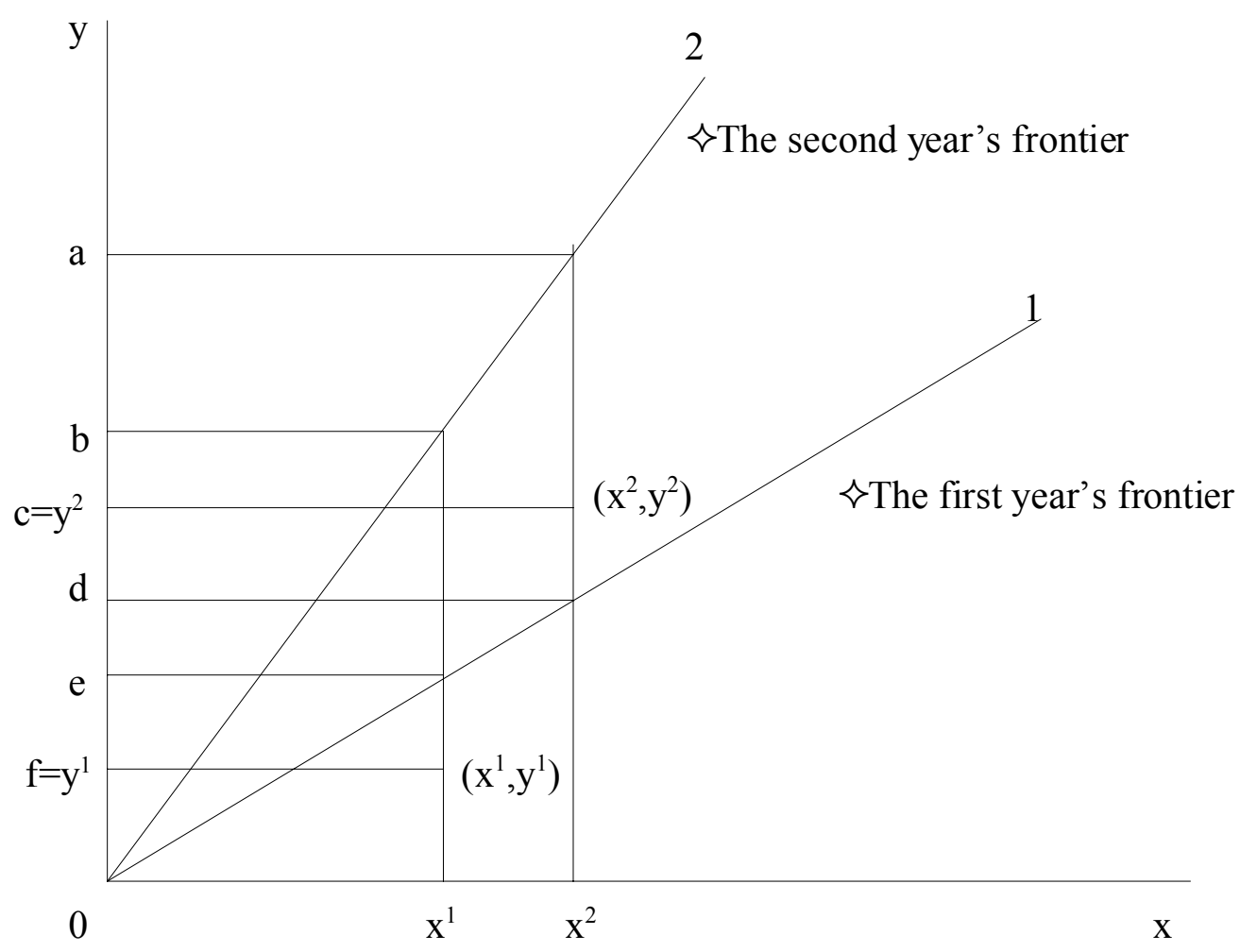

Figure 1 Output Increasing Technical Efficiency and the Output Oriented Malmquist Productivity Index. 
observations. Observations on the constructed frontiers are, in the literature, referred to as best practice production units, or best practice. By following Førsund and Hjalmarsson (1979), the output increasing technical efficiency under CRS, E3, for an enterprise in year 1 is defined as the ratio of observed output (0f) to the output level predicted (0e) by that year's production frontier (01), which can be written as ${ }^{5}$

$$
\mathrm{E} 3{ }_{11}=0 \mathrm{f} / 0 \mathrm{e}
$$

while the output increasing technical efficiency for the enterprise in year 1 against the second year's production frontier $(02)$ is

$$
\mathrm{E} 3_{21}=0 \mathrm{f} / 0 \mathrm{~b}
$$

where the first subscript refers to the frontier upon which the observations (represented by the second subscript) are evaluated in terms of technical efficiency. E3 $3_{22}$ and $E 3_{12}$ are also similarly defined. The value of $E 3_{11}$ and $E 3_{22}$, by definition, goes between 0 and 1 . A value of unity for $\mathrm{E} 3_{11}$, for instance, means that the production unit is $100 \%$ efficient technically, while a value of 0.5 implies that the production unit achieves only $50 \%$ technical efficiency. $\mathrm{E}_{12}$ may assume a value that exceeds unity in case of technical progress, because production units in year 2 may produce above the production frontier for year 1 as with the observation $\left(\mathrm{x}^{2}, \mathrm{y}^{2}\right)$ in Figure 1. Under the assumption of constant returns to scale (CRS), with reference to Figure 1, the output-oriented Malmquist productivity index can be defined as the geometric mean of the first and second period indices as

$$
M_{o}=\left[| \frac { 0 c / 0 a } { o f / o b } | \left(\left.\frac{0 c / 0 d}{0 f / 0 e}\right|^{1 / 2}\right.\right.
$$

Using technical efficiency notation, it is equivalent to

$$
\mathrm{M}_{\mathrm{o}}=\left[\left(\mathrm{E} 3_{22} / \mathrm{E} 3_{21}\right) \cong\left(\mathrm{E} 3_{12} / \mathrm{E} 3_{11}\right)\right]^{1 / 2}
$$

This definition is from Färe et al. (1994), but the notations for distance function are replaced by technical efficiency measures. A direct interpretation of $M_{0}$ is that productivity improvement can be measured as the ratio of the second year's technical efficiency to the first year's. However, since the frontier chosen for the measurement of technical efficiency appears to be arbitrary, the geometric mean of the indices based on both years' frontiers is 
taken as a compromise. The Malmquist productivity index, $\mathrm{M}_{0}$, can be multiplicatively decomposed into two parts as follows

$$
\begin{aligned}
& \mathrm{M}_{\mathrm{o}}=\left[\left(\mathrm{E} 3_{22} / \mathrm{E} 3_{21}\right) \cong\left(\mathrm{E} 3_{12} / \mathrm{E} 3_{11}\right)\right]^{1 / 2} \\
& =\left(\mathrm{E} 3_{22} / \mathrm{E} 3_{11}\right) \cong\left[\left(\mathrm{E} 3_{12} / \mathrm{E} 3_{22}\right) \cong\left(\mathrm{E} 3_{11} / \mathrm{E} 3_{21}\right)\right]^{1 / 2} \\
& =[(0 \mathrm{c} / 0 \mathrm{a}) /(0 \mathrm{f} / 0 \mathrm{e})] \cong[(0 \mathrm{a} / 0 \mathrm{~d}) \cong(0 \mathrm{~b} / 0 \mathrm{e})]^{1 / 2}=\mathrm{MC} \cong \mathrm{MF}
\end{aligned}
$$

where $\mathrm{MC}=\mathrm{E} 3_{22} / \mathrm{E} 3_{11}$, and $\mathrm{MF}=\left[\left(\mathrm{E} 3_{12} / \mathrm{E} 3_{22}\right) \cong\left(\mathrm{E} 3_{11} / \mathrm{E} 3_{21}\right)\right]^{1 / 2} . \mathrm{MC}$ is the ratio of technical efficiency evaluated using observations from year $2\left(E 3_{22}\right)$ to the efficiency evaluated using observations only from year 1. It measures the improvement in technical efficiency between the two years (catching-up effect). MF is the geometric mean of the frontier shift based on observations from both years, which is interpreted as technical change. Values of $M_{0}, M C$, and MF, which exceed unity, stand for improvement in total factor productivity, technical efficiency, and technical progress, while values that are less than unity mean the opposite.

In order to calculate the productivity of enterprise k' between 1 and 2 , we need to solve four different linear-programming problems: E3 $3_{12}, E 3_{22}, E 3_{11}$, and E3 $3_{21}$. For each $\mathrm{k}^{\prime}=1, \ldots, \mathrm{K}$,

$$
\begin{aligned}
& \left(E 3_{11}\left(x^{k^{\prime}, 1}, y^{k^{\prime}, 1}\right)\right)^{-1}=\max \theta^{k^{\prime}} \\
& \text { subject to } \\
& \begin{array}{lc}
\theta^{k^{\prime}} y_{m}^{k^{\prime}, 1} \leq_{k=1}^{K} z^{k, 1} y_{m}^{k, 1} & m=1, \ldots, M \\
{ }^{K} z^{k, 1} x_{n}^{k, 1} \leq x_{n}^{k^{\prime}, 1} & n=1, \ldots, N \\
{ }_{k=1}^{k, 1} \geq 0 & k=1, \ldots, K
\end{array}
\end{aligned}
$$

The computation of $E_{22}$ is exactly like the above, where 2 is substituted for subscript 1.

Two of the distance functions used to construct the Malmquist index require information from two periods. The first of these is computed for observation k' as, 
$\left(E 3_{12}\left(x^{k^{\prime}, 2}, y^{k^{\prime}, 2}\right)\right)^{-1}=\max \theta^{k^{\prime}}$

subject to

$$
\begin{array}{lc}
\theta^{k^{\prime}} y_{m}^{k^{\prime}, 2} \leq{ }_{k=1}^{K} z^{k, 1} y_{m}^{k, 1} & m=1, \ldots, M \\
{ }^{K} z^{k, 1} x_{n}^{k, 1} \leq x_{n}^{k^{\prime}, 2} & n=1, \ldots, N \\
k=1 & k=1, \ldots, K
\end{array}
$$

In empirical applications, the above formulations may produce results of technical regress, which are usually difficult to interpret. In order to avoid such results, in this study, restrictions will be imposed by including best practice observations from the first year when the second year's frontier is generated.

\section{Data}

The data used for empirical estimation come from two enterprise surveys conducted by the Chinese Academy of Social Sciences (CASS) in 1990 and 1996. The first survey, which has been used in Groves et al. $(1994,1995)$ and Li (1997), contains annual data from 769 state-owned enterprises between 1980 and 1989. The second survey includes mostly the same SOEs between 1990 and 1994. More than 300 variables are covered in the data, including details of enterprises' real and financial accounts, price information, and internal incentives. The sample enterprises represent 36 two-digit industries in mining, logging, utilities, and manufacturing and are located in four provinces (Jiangsu, Jilin, Shanxi, and Sichuan).

\section{A. Output, Inputs, and their Deflator}

When dealing with a panel data set as comprehensive as ours, the value-added output measure together with capital and total employment have been commonly used in practice. Because this type of data covers different industrial sectors, using value-added plus capital and total employment to estimate a value-added production function would make observations across industries more comparable. Another convention in this line of research is to use gross output plus capital, employment, and intermediate input in the estimation of production functions. However, this method would make the cross industrial observations less comparable, since the material used in one industry may not be used in another industry.

In this study, we take another approach to overcome the comparability problem with this type of data. We assume that each sector has its own production function. The benefit of this is that comparisons, for instance with regard to technical efficiency, are made after 
production functions for individual industries have been estimated. Another advantage is that disaggregation of inputs other than labor and capital becomes more reasonable. For one thing, materials within each industry are more comparable. For another, energy usage is also for more or less similar purposes within an industry.

To approximate the production technology in individual industries as precisely as possible, disaggregated labor inputs of production workers, technicians, and management personnel were chosen from the data. For intermediate inputs, annual costs of material, electricity, coal, and oil can be found as well. Because the cost shares of coal and oil in the total cost of non-labor inputs are negligible, coal and oil were later excluded from our analysis. The deflator for material was constructed using the annual percentage increase in material price reported in the data, and the deflator for electricity was found in the Statistical Yearbook of China. Capital was measured as total net fixed assets for production purpose in fixed prices. The capital deflator came from the Statistical Yearbook of China.

Output is measured as gross output at fixed price (1980 price), which was reported directly in the data. Using 1980 prices as a base to convert output of later years into a comparable measure has been a controversial issue in the Chinese enterprise studies. In Li (1997), 1990 market price deflators were constructed in order to reflect the real value of output produced in SOEs. However, according to the Chinese practice, for comparison purpose, SOEs have simply been required to report their gross output value by multiplying the quantity of their output with a fixed price issued by the statistical authorities. Since the establishment of the People's Republic of China, there have been only five fixed prices issued by the government in 1952, 1957, 1970, 1980, and 1990 (SSB, 1993, page 16). On the other hand, gross output in current prices may consist of values calculated using both market and planned prices. Therefore, the price deflator obtained from dividing the gross output at current prices by the gross output at fixed prices is not a really consistent deflator. ${ }^{6}$

\section{B. Reform and Characteristic Variables}

There are other variables that might be helpful in identifying the determinants of technical efficiency and productivity growth. Although productivity is fundamentally important in the evaluation of enterprise performance, it is only one of the necessary conditions for a successful firm. Since many SOEs' financial performance have been far from satisfactory, it would be interesting to make an assessment on the relationship between profitability of an enterprise and its productivity performance. We will use annual profit as our profit variable. As to the impact of incentive schemes on enterprise productivity, several 
variables can be used as far as the data are concerned. Relevant variables involve flexible wage, retained profits, relative salary of managers to that of workers, etc. Other factors that affect productivity may include education levels of employees (the proportion of employees with high school education or higher ${ }^{7}$ ), investment in fixed capital, capacity utilization, age of the enterprise, and the proportion of non-production workers to the total.

We are also particularly interested in the two characteristic variables: scale and administrative levels. According to the statistical authority in China, SOEs are classified into three scale groups: large, medium, and small. SOEs are supervised at different levels of government (central, province, region, and county). Centrally administered SOEs are usually large and county managed ones are usually small. Depending on number of observations available for each two-digit industry, 17 two-digit industries were chosen for analysis:

(1) Coal Industry

(5) Construction Materials and Other Non-Metal Mining

(10) Food Manufacturing

(14) Textile Industry

(16) Animal Skin Product Manufacturing

(19) Paper and Paper Products Manufacturing

(20) Printing Industry

(26) Chemical Industry

(27) Medicine Industry

(29) Rubber Product Manufacturing

(31) Construction Materials and Other Non-Metal Mine Products

(32) Black Metal Production and Processing

(35) Machinery Industry

(36) Communication and Transportation Equipment Manufacturing

(37) Electrical Machinery and Material Manufacturing

(38) Electronics and Communication Equipment Manufacturing

(39) Industrial Instrument and Measurement Equipment Manufacturing

The numbers are industry classification codes from the Chinese statistical authorities.

\section{Empirical Results}

17 two-digit industries are chosen for empirical estimations. Those industries that were left out have too few observations (less than four). Although deterministic frontier methods such as DEA usually require much less observations than stochastic frontier 
methods, lack of cross-section observations for some industries in our data does have a negative effect on estimation results. For instance, when there are only about 10 observations in each cross-section, average technical efficiencies tend to be unusually high. However, we expect that this problem would be less severe when it comes to improvement in efficiency and technical change. In the first part of the section, DEA and Malmquist estimation results are discussed by industry sector. Regression analyses were also performed on estimated technical efficiency measures. The results are presented in the second part of the section.

\subsection{DEA and Malmquist Index Results}

The estimates of $\mathrm{E}_{11}, \mathrm{M}_{\mathrm{o}}, \mathrm{MC}$, and $\mathrm{MF}$ are reported in Tables 1, 2, 3 and 4. The results are presented in four groups. Machinery industry and textiles have a relatively larger number of cross-section observations, so they were grouped by themselves. For other industries, they are included either in the group of heavy industries or in that of light industries. Only a few extreme observations were excluded from the data. The estimation strategy used in obtaining DEA estimates was to keep as many observations as possible and detailed data cleaning work was kept to the minimum due to the relatively large size of the data set. Fortunately, there are only a handful of seemingly too high values for the Malmquist index and its components, and they were not excluded as outliers (e.g., 9.87 in Table 2). In one case, the Malmquist index between 1980 and 1994 was too large (49.96 in Table 2), but this number was not involved in the regression analysis (only between-year index was used).

In Table 1, the lower levels of average efficiency for machinery and textile industries might be due to their larger cross-section, and the higher levels of average efficiency between 1990-94 can be also attributed to the reduction in the number of observations during the period. Otherwise, it is consistent with the belief that technical efficiency had been improved since the early 1990s. There does not seem to be an obvious time trend in technical efficiency during the entire data period. On the whole, the levels of technical efficiency among SOEs in China appear to fall in the 50\%-80\% interval. The higher efficiency level in heavy and light industries might be attributed to the lack of observations in some industries as mentioned above.

In Table 5, we calculated the distribution of frontier enterprises (best practice) across different scales. Small scale seems to have more enterprises producing on their industry production frontier than others during the data period, but the differences are not large. In Table 6, enterprises supervised by region government have relatively more frontier producers. On the other hand, Jiangsu had more best-practice SOEs than other provinces in 
relative terms (Table 7). In all the three tables, otherwise, the distributions of best practice across scale, administration, and provinces are fairly even. This provides an interesting case for regression analysis.

As to the results regarding the Malmquist index, productivity growth was seen in all the sectors, but textile showed productivity decrease in 4 years. The decomposition of productivity growth into efficiency change and technical progress reveals an interesting phenomenon. Efficiency improvement was rather rare in all four sectors. Most of the productivity growth came from technical progress. This can be a distorted picture as far as Chinese enterprise data are concerned. One scenario is that most enterprises had been producing well below their production frontier including best practice SOEs. The frontier was formed through best practice SOEs in our estimation. In the reform process the potential for the best SOEs to improve technical efficiency was very large. Therefore, as the best SOEs improve their technical efficiency, they raise the production frontiers. Technical progress was thus exaggerated and technical efficiency improvement for non-frontier enterprises underestimated.

\subsection{Regression Analysis ${ }^{8}$}

There are three sets of results for regression analysis. The first is the regression of DEA efficiency estimates on explanatory variables. For analysis of best practice, we also created a qualitative variable by setting efficiency scores with values less than unity to zero. The second is the regression of the Malmquist index and its components on explanatory variables. Only quantitative dependent variables were used in this case. The third set of results was obtained by using qualitative dependent variables derived from the Malmquist index and its components.

The explanatory variables include age of the enterprise, the ratio of flexible wage to total wage, the share of high school graduates or higher of total employees, capacity utilization, and dummies for provinces, scale, administration levels, industries, and years. Explanatory variables that were excluded from our final estimations are: total profits, retained profits, relative salary of managers to that of workers, investment in fixed capital, and the proportion of non-production workers to the total. These variables were not statistically significant in our preliminary estimations and usually had much more missing observations than those kept in the final estimations.

Regression results on the determinants of technical efficiency are presented in Table 10. Tobit models were used when E3 was the dependent variable, while Probit models were 
employed when E3* (a 0-1 variable, i.e., 0 for less than $100 \%$ efficient and 1 for $100 \%$ efficient enterprises) was the dependent variable. In the case of the Tobit model results, the random effects model was favoured, whereas the random effects with the Probit model was not statistically significant. Age, education, and flexible wages all had positive effects on technical efficiency, with education the highest (0.0886). Medium SOEs were significantly less efficient than small SOEs. Jiangsu province was definitely the most efficient among the four provinces of the sample. In the case of the Probit model results, flexible wages and education had highly significant effects over the probability of producing on the frontier, but the effect of the age variable became statistically insignificant. Jiangsu came again first in terms of frontier affects.

As to the influence of administration levels, the random effect model produced somewhat different result from the ordinary Tobit model. But in both cases, centrally administrated SOEs were the least efficient. This made a stark contrast with the results of the Probit model on large scale. According to the Tobit model result on best practice, large scale increases the probability of being on the production frontier. Less than one-third of large SOEs are supervised by the central government through industrial ministries. The worst-case scenario is a medium SOE administered by the central government.

In Table 11, the Malmquist index and its components (efficiency and technical changes) are used as dependent variables. Explanatory variables (flexible wages, education, and capacity utilization) in the regression are in first difference, since the Malmquist index reflects the change in productivity between two years. Random effect models were all rejected in both the linear and non-linear formulation (i.e. the Tobit model for technical progress) because the first difference nature of the Malmquist index took away the individual effects. The regression results are very encouraging: flexible wages and education have a positive influence on productivity growth as a whole, but the influence was mainly through improvement in technical efficiency. Capacity utilization became insignificant, perhaps because of lack of variations in this variable. Jiangsu province is a front-runner in terms of improvement in technical efficiency as well as technical progress. The years, 1983, 1990, and 1993 had noticeable improvement in productivity. For 1983 and 1993, the improved productivity seems to come mainly from technical progress.

In Table 12, the dependent variables are 0-1 variables for the Malmquist index, i.e., efficiency change ( 0 for negative or no change and 1 for positive change), and technical progress ( 0 for no change and 1 for positive change). Again, flexible wage had a positive impact on the probability of an enterprise to have a productivity improvement via 
improvement in technical efficiency. Jiangsu province achieved productivity improvements mainly through technical progress. This result is consistent with the one in Table 11. Another interesting finding is that large-scale enterprises were more likely to have productivity improvements, which might be regarded as a confirmation of the government's strategy of "grasp the large and release the small." The high probability of productivity improvement in large SOEs was driven by investment in new technology. It is also interesting to relate this finding with that in Table 11: large scale does not guarantee productivity improvement, although it increases the probability of a breakthrough to growth. Education is not significant in Table 12.

Overall the decomposition and the regressions provided interesting results. It seems that explanatory variables can be grouped into two categories. Education and flexible wage have positive impact on productivity through efficiency improvement, while province and large scale mainly affect technical progress. Put it another way, physical capital (reflected by scale, province) affects technical progress, while incentive schemes and human capital are more important for efficiency improvement (as with flexible wage and education).

On average, the improvement in technical efficiency is far from satisfactory, while technical progress dominates productivity growth. So, the potential for productivity improvement in SOEs is large. On the other hand, the best practice SOEs may have played the role of leaders throughout the data period. As they improved their production efficiency, it was very difficult for others to catch up. In this case, the average and the best practice SOEs may simply belong to entirely different categories of producers in terms of technology, quality of human capital, managerial capacity, and external environment. Therefore, it is not so unreasonable that the recent government policy encouraged takeovers of less efficient SOEs by the more efficient ones.

\section{Conclusions}

In this study, we have investigated the productivity performance of SOEs, using a relatively large panel. The measured average efficiency levels of SOEs were low (mostly less than $70 \%$, sometimes around only $50 \%$ ), when sufficient observations could be used for some industrial branches. This is consistent with findings in previous studies such as $\mathrm{Wu}$ (1993), Liu and Zheng (1998), and Zheng, Liu, and Bigsten (1998). On average, there had been productivity growth in the sample SOEs. However, the decomposition shows that the SOE sector have relied on capital investment rather than on improvement in technical efficiency. Best practice SOEs seem to be more or less evenly distributed across scales, administrative 
levels, and provinces in the data. However, according to our regression analyses, large scale was one of the determinants of best practice and technical progress. On the other hand, large SOEs did not have advantages in terms of average technical efficiency and efficiency improvement over medium and small SOEs. This implies that even large SOE is not a homogeneous group with respect to technical efficiency.

Flexible wages and education had significant and positive impacts on technical efficiency and productivity improvement, and can be considered determinants of best practice SOEs. However, the effect of education may require more preconditions than that of flexible wages. Incentive schemes have a significant impact on the direction of efficiency change, while the effect of education takes place only when the change is positive. Jiangsu province seems to have succeeded in bringing about some efficiency improvements, instead of relying solely on investment in new technology. Centrally administrated SOEs were among the least efficient assuming everything else fixed.

Our empirical findings are not inconsistent with the recent government policy concerning redundancies, technical up-grading, and the modern enterprise system. These policy emphases do address the key problems deeply rooted in the SOE sector, i.e., low efficiency, incompetence, and inability to separate management from state interference. It is probably fair to say that China's enterprise reforms have made considerable progress in the area of productivity growth in the SOE sector since the late 1970s. Particularly, large SOEs were more able to play the role of best practice firms than medium and small SOEs. Nevertheless, these achievements are far from satisfactory by international standards. More drastic reform measures are called for, including complete or partial privatisation. However, the reform of large SOEs is a more complex task than that of others. When privatisation appears not to be an option in sectors such as basic, military, and pillar industries, for the time being, the restructuring program of 1994 seems to be an alternative with less economic and political risks. Getting rid of policy burdens and the development of the modern industrial corporate culture are time-consuming and may take years to accomplish. If the ultimate goal is to privatise most of the large SOEs, privatisation might be more likely to succeed in the absence of policy burdens and when the modern enterprise system is well established within the SOE sector. After all, one has to pay due attention to the lessons of the Eastern Europe and the former Soviet Union experience, for instance, summarised in Nolan (1995) and Stiglitz (1999). The big bang solution is not always the most efficient one. 


\section{References}

Chen, Kuan, Jefferson, Gary H., Rawski, Thomas G., Wang, Hongchang, and Zheng, Yuxin, "Productivity Change in Chinese Industry, 1953-1985.' J. Comp. Econom. 12, 4:570-591, 1988.

Cornwell, Christopher, Schmidt, Peter, and Sickles, Robin C., "Production Frontiers with Cross-Sectional and Time-Series Variation in Efficiency Levels." J. Econometrics, 46, 1-2:185-200, Oct.-Nov. 1990.

Färe, Rolf, Grosskopf, Shawna, He, Y., and Horvath, J., "Industrial Productivity Growth in China: 1980-84 VS. 1984-85.” In Rolf Färe and Shawna Grosskopf, Intertemporal Production Frontiers: With Dynamic DEA, pp. 98-116, Kluwer Academic Publishers, 1996.

Färe, Rolf, Grosskopf, Shawna, Norris, Mary, and Zhang Zhongyang, "Productivity

Growth, Technical Progress, and Efficiency Change in Industrialised Countries," American Economic Review, Vol. 84, No.1, March, 1994, pp. 66-83.

Førsund, F.R. and Hjalmarsson, “Generalised Farrell Measures of Efficiency: An application to Milk Processing In Swedish Dairy Plants,” Economic Journal, 89, 294-315, 1979.

Groves, Theodore, "Autonomy and Incentives in Chinese State Enterprises," Quarterly Journal of Economics, February 1, 1994, v. 109, iss. 1, pp. 183-209.

Groves, Theodore, "China's Evolving Managerial Labor Market," Journal of Political Economy, August 1, 1995, v. 103, iss. 4, pp. 873-92.

Jefferson, Gary H., Rawski, Thomas G., and Zheng, Yuxin "Chinese Industrial Productivity: Trends, Measurement Issues, and Recent Developments.” J. Comp. Econom. 23, 2:146-180, 1996.

Jefferson, Gary H., Rawski, Thomas G., and Zheng, Yuxin, 'Has Productivity in China's State-owned Industrial Enterprises Really Increased During the Reform Period?’ Jingji Yanjiu [Economic Research, Beijing] 10:77-80, 1994.

Jefferson, Gary H., and Singh, Inderjit, “'Ownership and Performance in Chinese Industry: A Review of the Literature.' In Gary H. Jefferson and Inderjit Singh, Eds., Reform, Ownership, and Performance in Chinese Industry. 1993.

Lau, Kam-Tim, and Brada, Joseff C., "Technological Progress and Technical Efficiency in

Chinese Industrial Growth: A Frontier Production Function Approach." China Econom. Rev., 1, 2:114-124, 1990.

Li, Wei, "The Impact of Economic Reform on the Performance of Chinese State Enterprises, 1980-1989," Journal of Political Economy, October 1997, v. 105, iss. 5, 1080-1106. 
Lin, J. Y. and Tan, G., "Policy Burdens, Accountability, and the Soft Budget Constraint," The American Economic Review, 89, 2:426-431, May 1999.

Lin, Justin Yifu, Fang Cai, and Zhou Li, "Competition, Policy Burdens, and State-owned Enterprise Reform," The American Economic Review, 88, 2: 422-427, May, 1998.

Liu, Xiaoxuan and Jinghai Zheng, "Determinants of Technical Efficiency in State

Enterprises: 1985-1994.” Jingji Yanjiu [Economic Research, Beijing], No 1 (357), Jan. 20, 1998.

Lo, D., “Re-appraising China's State-owned Industrial Enterprises, 1980-96," Cambridge Journal of Economics, 23, 693-718, 1999.

Nolan, Peter, China's Rise, Russia's Fall: Politics, Economics and Planning in the Transition from Stalinism, London: Macmillan Press LTD, 1995.

Nolan, P. and Wang, X., "Beyond Privatization: Institutional Innovation and Growth in China’s Large State-owned enterprises,” World Development, 27 (1), 169-200, 1999.

Parker, Elliott, "The Effect of Scale on the Response to Reform by Chinese State-Owned Construction Units,” Journal of Development Economics, April 1997, 52, 2:331-53.

Rawski, Thomas G., "Productivity Change in Chinese Industry: Problems of Measurement." Unpublished, 1986.

Wang, Yong, "China's Domestic WTO Debate," The China Business Review, Jan.-Feb., 2000.

Smyth, R., "Should China be Promoting Large-Scale Enterprises and Enterprise Groups," World Development, 28, 4:721-737, 2000.

SSB, Explanations of Major Industrial Statistical Indicators (Gongye Tongji Zhuyao Zhibiao Jieshi), State Statistical Bureau, China City Printing House, Beijing, 1993.

Stiglitz, Joseph, "Quis Custodiet Ipsos Custodes?" Challenge, 42, 6:26-67, November/December, 1999.

Woo, Wing Thye, Hai, Wen, Jin, Yibiao, and Fan, Gang, “How Successful Has Chinese Enterprise Reform Been? Pitfalls in Opposite Biases and Focus.' J. Comp. Econom. 18, 3:410-437, 1994.

World Bank, China 2020: Development Challenges in the New Century, Washington D.C., 1997.

$\mathrm{Wu}$, Yanrui, "Technical Efficiency and Firm Attributes in the Chinese Iron and Steel Industry.” Int. Rev. App. Econom, 10, 2:235-48, May 1996.

Wu, Yanrui, "Productivity Growth, Technological Progress, and Technical Efficiency Change in China: A Three-Sector Analysis.” J. Comp. Econom. 21, 2:207-29, Oct. 
1995.

Wu, Yanrui, “Productive Efficiency in Chinese Industry.” Asian-Pacific Econom. Lit. 7, 2:58-66, 1993.

Zheng, Jinghai, Xiaoxuan Liu and Arne Bigsten, "Ownership Structure and Determinants of Technical Efficiency: an Application of Data Envelopment Analysis to Chinese Enterprises (1986-1990).” J. Comp. Econom., 26, 3:465-484, Sept. 1998. 
Table 1 Technical Efficiency in SOEs (1980-94)

\begin{tabular}{llllllllllllllllllll}
\hline \multicolumn{1}{c}{ Machinery Industry } & \multicolumn{3}{c}{ Textile Industry } & \multicolumn{4}{c}{ Heavy Industries } & \multicolumn{5}{c}{ Light Industries } \\
\multicolumn{1}{l}{ Year } & N & Mean & Min & Std & N & Mean & Min & Std & N & Mean & Min & Std & N & Mean & Min & Std \\
\hline 80 & 108 & 0.62 & 0.13 & 0.22 & 64 & 0.73 & 0.37 & 0.16 & 145 & 0.71 & 0.01 & 0.24 & 123 & 0.68 & 0.05 & 0.35 \\
81 & 135 & 0.57 & 0.09 & 0.20 & 75 & 0.68 & 0.35 & 0.20 & 181 & 0.67 & 0.06 & 0.28 & 147 & 0.74 & 0.17 & 0.27 \\
82 & 138 & 0.54 & 0.12 & 0.21 & 86 & 0.67 & 0.19 & 0.19 & 186 & 0.75 & 0.06 & 0.23 & 154 & 0.78 & 0.08 & 0.23 \\
83 & 137 & 0.58 & 0.20 & 0.22 & 89 & 0.20 & 0.07 & 0.16 & 190 & 0.76 & 0.06 & 0.23 & 157 & 0.79 & 0.05 & 0.23 \\
84 & 145 & 0.56 & 0.18 & 0.22 & 93 & 0.48 & 0.12 & 0.23 & 196 & 0.78 & 0.08 & 0.21 & 164 & 0.78 & 0.07 & 0.23 \\
85 & 142 & 0.52 & 0.17 & 0.21 & 95 & 0.49 & 0.12 & 0.25 & 199 & 0.76 & 0.06 & 0.22 & 170 & 0.81 & 0.07 & 0.21 \\
86 & 145 & 0.52 & 0.16 & 0.21 & 94 & 0.48 & 0.10 & 0.28 & 200 & 0.76 & 0.11 & 0.22 & 172 & 0.79 & 0.06 & 0.23 \\
87 & 143 & 0.53 & 0.16 & 0.21 & 95 & 0.49 & 0.08 & 0.28 & 201 & 0.75 & 0.09 & 0.22 & 174 & 0.69 & 0.11 & 0.29 \\
88 & 143 & 0.52 & 0.14 & 0.20 & 95 & 0.49 & 0.12 & 0.26 & 200 & 0.75 & 0.12 & 0.22 & 173 & 0.79 & 0.11 & 0.22 \\
89 & 146 & 0.52 & 0.12 & 0.22 & 95 & 0.48 & 0.09 & 0.27 & 201 & 0.76 & 0.09 & 0.23 & 174 & 0.78 & 0.20 & 0.23 \\
90 & 141 & 0.68 & 0.25 & 0.19 & 89 & 0.69 & 0.26 & 0.20 & 177 & 0.87 & 0.30 & 0.16 & 176 & 0.86 & 0.30 & 0.17 \\
91 & 142 & 0.71 & 0.23 & 0.20 & 90 & 0.71 & 0.33 & 0.18 & 177 & 0.73 & 0.15 & 0.27 & 177 & 0.85 & 0.19 & 0.18 \\
92 & 142 & 0.63 & 0.18 & 0.19 & 90 & 0.69 & 0.25 & 0.20 & 177 & 0.84 & 0.25 & 0.18 & 177 & 0.81 & 0.26 & 0.21 \\
93 & 142 & 0.59 & 0.16 & 0.19 & 90 & 0.23 & 0.04 & 0.20 & 177 & 0.82 & 0.28 & 0.20 & 177 & 0.78 & 0.17 & 0.23 \\
94 & 142 & 0.62 & 0.16 & 0.21 & 90 & 0.66 & 0.17 & 0.22 & 177 & 0.75 & 0.18 & 0.23 & 177 & 0.68 & 0.10 & 0.30 \\
\hline
\end{tabular}

Table 2 Malmquist Index for SOEs (1980-94)

\begin{tabular}{llllllllllllllllllll}
\hline \multicolumn{4}{c}{ Machinery Industry } & \multicolumn{4}{c}{ Textile Industry } & \multicolumn{4}{c}{ Heavy Industries } & \multicolumn{6}{c}{ Light Industries } \\
Year & Mean & Min & Max & Std & Mean Min & Max & Std & Mean Min & Max & Std & Mean Min & Max & Std \\
\hline $80 / 81$ & 0.94 & 0.23 & 1.60 & 0.27 & 1.04 & 0.76 & 1.42 & 0.15 & 1.04 & 0.15 & 7.89 & 0.70 & 1.00 & 0.08 & 2.37 & 0.31 \\
$81 / 82$ & 1.14 & 0.43 & 4.98 & 0.50 & 0.97 & 0.16 & 1.40 & 0.19 & 1.06 & 0.61 & 2.82 & 0.30 & 1.08 & 0.39 & 2.47 & 0.26 \\
$82 / 83$ & 1.13 & 0.50 & 2.23 & 0.25 & 1.29 & 0.64 & 8.93 & 1.13 & 1.10 & 0.26 & 2.34 & 0.23 & 1.16 & 0.38 & 6.68 & 0.52 \\
$83 / 84$ & 1.14 & 0.46 & 2.28 & 0.24 & 1.04 & 0.15 & 2.41 & 0.27 & 1.06 & 0.63 & 3.91 & 0.27 & 1.18 & 0.60 & 8.66 & 0.65 \\
$84 / 85$ & 1.11 & 0.49 & 2.12 & 0.21 & 1.02 & 0.61 & 1.64 & 0.18 & 1.04 & 0.19 & 3.55 & 0.29 & 1.10 & 0.56 & 2.32 & 0.25 \\
$85 / 86$ & 1.06 & 0.51 & 3.29 & 0.29 & 0.98 & 0.39 & 2.13 & 0.24 & 1.13 & 0.20 & 5.72 & 0.48 & 1.04 & 0.52 & 2.05 & 0.20 \\
$86 / 87$ & 1.10 & 0.48 & 2.73 & 0.27 & 1.04 & 0.36 & 1.85 & 0.21 & 1.06 & 0.37 & 2.01 & 0.20 & 1.14 & 0.57 & 3.56 & 0.36 \\
$87 / 88$ & 1.11 & 0.44 & 2.13 & 0.24 & 0.96 & 0.32 & 1.79 & 0.24 & 1.11 & 0.60 & 3.91 & 0.31 & 1.17 & 0.54 & 5.33 & 0.50 \\
$88 / 89$ & 1.04 & 0.30 & 1.85 & 0.23 & 0.93 & 0.34 & 1.94 & 0.24 & 1.01 & 0.11 & 1.71 & 0.21 & 1.10 & 0.51 & 3.73 & 0.37 \\
$89 / 90$ & 1.13 & 0.43 & 3.38 & 0.52 & 1.21 & 0.22 & 4.30 & 0.69 & 1.14 & 0.42 & 4.46 & 0.56 & 1.20 & 0.56 & 3.34 & 0.46 \\
$90 / 91$ & 0.93 & 0.45 & 1.44 & 0.16 & 0.93 & 0.36 & 1.18 & 0.14 & 1.03 & 0.19 & 6.01 & 0.43 & 0.96 & 0.45 & 1.67 & 0.16 \\
$91 / 92$ & 1.06 & 0.43 & 1.90 & 0.18 & 1.0 & 0.55 & 1.51 & 0.16 & 1.06 & 0.17 & 2.64 & 0.28 & 1.05 & 0.54 & 1.79 & 0.17 \\
$92 / 93$ & 1.12 & 0.68 & 2.12 & 0.22 & 1.17 & 0.30 & 9.87 & 0.96 & 1.11 & 0.67 & 2.70 & 0.22 & 1.11 & 0.59 & 2.16 & 0.22 \\
$93 / 94$ & 1.07 & 0.39 & 2.02 & 0.20 & 1.17 & 0.15 & 3.81 & 0.52 & 1.10 & 0.53 & 1.56 & 0.17 & 1.12 & 0.57 & 3.24 & 0.27 \\
$80 / 94$ & 1.84 & 0.30 & 6.31 & 0.87 & 1.65 & 0.46 & 5.64 & 0.91 & 2.10 & 0.31 & 49.96 & 5.04 & 2.18 & 0.17 & 13.18 & 2.01 \\
\hline
\end{tabular}


Table 3 Efficiency Change in SOEs (1980-94)

\begin{tabular}{lllllllllllllllllllll}
\hline \multicolumn{4}{c}{ Machinery Industry } & \multicolumn{4}{c}{ Textile Industry } & \multicolumn{4}{c}{ Heavy Industries } & \multicolumn{5}{c}{ Light Industries } \\
Year & Mean & Min Max & Std & Mean Min & Max & Std & Mean Min & Max & Std & Mean Min & Max & Std \\
\hline $80 / 81$ & 0.87 & 0.23 & 1.60 & 0.24 & 0.91 & 0.62 & 1.27 & 0.15 & 0.89 & 0.07 & 7.89 & 0.65 & 0.95 & 0.08 & 2.37 & 0.28 \\
$81 / 82$ & 0.98 & 0.33 & 4.04 & 0.41 & 0.93 & 0.16 & 1.40 & 0.19 & 1.01 & 0.54 & 2.80 & 0.29 & 0.99 & 0.39 & 2.17 & 0.22 \\
$82 / 83$ & 1.06 & 0.46 & 2.00 & 0.24 & 0.28 & 0.13 & 1.33 & 0.17 & 1.01 & 0.25 & 2.13 & 0.18 & 1.02 & 0.38 & 6.33 & 0.48 \\
$83 / 84$ & 0.98 & 0.40 & 1.85 & 0.22 & 1.01 & 0.15 & 1.96 & 0.25 & 0.98 & 0.62 & 3.69 & 0.25 & 0.99 & 0.39 & 2.21 & 0.21 \\
$84 / 85$ & 0.94 & 0.41 & 2.11 & 0.20 & 0.96 & 0.58 & 1.58 & 0.17 & 0.97 & 0.18 & 2.46 & 0.22 & 1.00 & 0.48 & 1.89 & 0.20 \\
$85 / 86$ & 0.99 & 0.49 & 3.12 & 0.27 & 0.93 & 0.36 & 2.01 & 0.22 & 1.01 & 0.20 & 5.38 & 0.39 & 0.95 & 0.45 & 1.71 & 0.16 \\
$86 / 87$ & 1.05 & 0.46 & 2.60 & 0.26 & 0.99 & 0.35 & 1.57 & 0.18 & 0.97 & 0.36 & 1.54 & 0.15 & 0.83 & 0.26 & 1.39 & 0.24 \\
$87 / 88$ & 0.98 & 0.40 & 1.81 & 0.21 & 0.92 & 0.32 & 1.71 & 0.23 & 0.97 & 0.51 & 3.86 & 0.27 & 1.06 & 0.54 & 4.20 & 0.37 \\
$88 / 89$ & 0.98 & 0.29 & 1.74 & 0.21 & 0.84 & 0.22 & 1.42 & 0.21 & 0.95 & 0.11 & 1.52 & 0.18 & 0.95 & 0.47 & 1.70 & 0.19 \\
$89 / 90$ & 1.08 & 0.43 & 3.13 & 0.46 & 1.10 & 0.21 & 4.30 & 0.65 & 1.06 & 0.42 & 4.46 & 0.51 & 1.03 & 0.42 & 2.50 & 0.36 \\
$90 / 91$ & 0.93 & 0.45 & 1.44 & 0.16 & 0.92 & 0.36 & 1.18 & 0.14 & 0.82 & 0.15 & 1.70 & 0.28 & 0.91 & 0.43 & 1.67 & 0.16 \\
$91 / 92$ & 0.89 & 0.42 & 1.71 & 0.16 & 0.92 & 0.50 & 1.42 & 0.15 & 1.01 & 0.17 & 2.58 & 0.26 & 0.94 & 0.52 & 1.47 & 0.13 \\
$92 / 93$ & 0.94 & 0.49 & 1.88 & 0.18 & 0.31 & 0.06 & 1.02 & 0.19 & 0.97 & 0.55 & 2.44 & 0.17 & 0.94 & 0.47 & 1.78 & 0.18 \\
$93 / 94$ & 1.01 & 0.32 & 1.64 & 0.18 & 1.12 & 0.15 & 3.60 & 0.44 & 0.99 & 0.46 & 1.46 & 0.14 & 0.96 & 0.48 & 2.52 & 0.21 \\
$80 / 94$ & 1.08 & 0.20 & 4.42 & 0.55 & 0.95 & 0.23 & 1.90 & 0.37 & 1.78 & 0.30 & 49.75 & 4.89 & 1.50 & 0.12 & 12.66 & 1.70 \\
\hline
\end{tabular}

Table 4 Technical Progress in SOEs (1980-94)

\begin{tabular}{|c|c|c|c|c|c|c|c|c|c|c|c|c|c|c|c|}
\hline \multirow[b]{2}{*}{ Year } & \multicolumn{3}{|c|}{ Machinery Industry } & \multicolumn{4}{|c|}{ Textile Industry } & \multicolumn{4}{|c|}{ Heavy Industries } & \multicolumn{4}{|c|}{ Light Industries } \\
\hline & Mean & Min Max & Std & Mean & Min & Max & Std & Mean & Min & Max & Std & Mean & Min & Max & Std \\
\hline $80 / 81$ & 1.08 & 1.001 .28 & & 1.15 & 1.00 & 1.29 & 0.09 & 1.33 & & & 0.79 & 1.06 & 1.00 & 1.76 & 0.12 \\
\hline $81 / 82$ & 1.16 & 1.001 .48 & 0.09 & 1.04 & 1.00 & 1.12 & 0.04 & 1.05 & & 1.33 & 0.06 & 1.09 & 1.00 & 1.86 & 0.13 \\
\hline $82 / 83$ & 1.07 & 1.001 .29 & 0.08 & 4.71 & 2.05 & 9.70 & 1.27 & 1.10 & 1.00 & 2.44 & 0.13 & 1.14 & 1.00 & 2.72 & 0.19 \\
\hline $83 / 84$ & 1.18 & 1.011 .67 & 0.12 & 1.02 & 1.00 & 1.23 & 0.03 & 1.08 & 1.00 & 1.50 & 0.09 & 1.20 & 1.00 & 8.66 & 0.63 \\
\hline $84 / 85$ & 1.18 & 1.001 .29 & 0.07 & 1.06 & 1.00 & 1.20 & 0.05 & 1.07 & 1.00 & 1.44 & 0.06 & 1.10 & 1.00 & 1.85 & 0.10 \\
\hline $85 / 86$ & 1.07 & 1.001 .16 & 0.05 & 1.06 & 1.00 & 1.46 & 0.06 & 1.11 & 1.00 & 2.61 & 0.19 & 1.10 & 1.00 & 2.05 & 0.12 \\
\hline $86 / 87$ & 1.05 & 1.001 .15 & 0.03 & 1.05 & 1.00 & 1.44 & 0.06 & 1.09 & 1.00 & 2.01 & 0.12 & 1.53 & 1.00 & 4.20 & 0.76 \\
\hline $87 / 88$ & 1.13 & 1.001 .57 & 0.09 & 1.04 & 1.00 & 1.15 & 0.04 & 1.16 & 1.00 & 1.90 & 0.19 & 1.10 & 1.00 & 4.12 & 0.25 \\
\hline $88 / 89$ & 1.06 & 1.001 .42 & 0.04 & 1.12 & 1.00 & 1.94 & 0.18 & 1.07 & 1.00 & 1.71 & 0.11 & 1.16 & 1.00 & 3.73 & 0.29 \\
\hline $89 / 90$ & 1.04 & 1.001 .31 & 0.05 & 1.11 & 1.00 & 2.54 & 0.20 & 1.07 & 1.00 & 1.57 & 0.12 & 1.16 & 1.00 & 2.13 & 0.18 \\
\hline $90 / 91$ & 1.01 & 1.001 .15 & 0.02 & 1.01 & 1.00 & 1.13 & 0.02 & 1.53 & 1.00 & 6.01 & 1.04 & 1.06 & 1.00 & 1.44 & 0.08 \\
\hline $91 / 92$ & 1.20 & 1.001 .60 & 0.12 & 1.09 & 1.00 & 1.44 & 0.09 & 1.05 & 1.00 & 1.52 & 0.08 & 1.12 & 1.00 & 1.79 & 0.14 \\
\hline $92 / 93$ & 1.20 & 1.032 .26 & 0.14 & 4.59 & 1.14 & 9.87 & 2.01 & 1.15 & 1.01 & 1.82 & 0.12 & 1.20 & 1.00 & 1.98 & 0.21 \\
\hline $93 / 94$ & 1.06 & 1.001 .29 & 0.07 & 1.04 & 1.00 & 1.87 & 0.10 & 1.12 & 1.00 & 1.45 & 0.09 & 1.18 & 1.00 & 2.33 & 0.19 \\
\hline $80 / 94$ & 1.72 & 1.192 .44 & 0.25 & 1.72 & 1.16 & 3.28 & 0.41 & 1.24 & 1.00 & 2.66 & 0.28 & 1.67 & 1.00 & 5.83 & 0.96 \\
\hline
\end{tabular}


Table 5 Number of Best Practice and Its Proportions by Scale (1980-1994)

\begin{tabular}{|c|c|c|c|c|c|c|c|c|c|}
\hline \multirow[t]{2}{*}{ Year } & \multicolumn{3}{|c|}{ Large SOEs } & \multicolumn{3}{|c|}{ Medium SOEs } & \multicolumn{3}{|c|}{ Small SOEs } \\
\hline & Total & Best & Share & Total & Best & Share & Total & Best & Share \\
\hline 1980 & 169 & 19 & 0.1124 & 371 & 48 & 0.1294 & 229 & 27 & 0.1179 \\
\hline 1981 & 169 & 22 & 0.1302 & 371 & 63 & 0.1698 & 229 & 31 & 0.1354 \\
\hline 1982 & 169 & 27 & 0.1598 & 371 & 61 & 0.1644 & 229 & 32 & 0.1397 \\
\hline 1983 & 169 & 28 & 0.1657 & 371 & 49 & 0.1321 & 229 & 33 & 0.1441 \\
\hline 1984 & 169 & 28 & 0.1657 & 371 & 56 & 0.1509 & 229 & 37 & 0.1616 \\
\hline 1985 & 169 & 31 & 0.1834 & 371 & 53 & 0.1429 & 229 & 44 & 0.1921 \\
\hline 1986 & 169 & 30 & 0.1775 & 371 & 62 & 0.1671 & 229 & 48 & 0.2096 \\
\hline 1987 & 169 & 26 & 0.1539 & 371 & 54 & 0.1456 & 229 & 41 & 0.1790 \\
\hline 1988 & 169 & 28 & 0.1657 & 371 & 57 & 0.1536 & 229 & 45 & 0.1965 \\
\hline 1989 & 169 & 30 & 0.1775 & 371 & 64 & 0.1725 & 229 & 49 & 0.2140 \\
\hline 1990 & 157 & 38 & 0.2420 & 342 & 87 & 0.2544 & 168 & 54 & 0.3214 \\
\hline 1991 & 157 & 29 & 0.1847 & 342 & 70 & 0.2047 & 168 & 42 & 0.2500 \\
\hline 1992 & 157 & 37 & 0.2357 & 342 & 75 & 0.2193 & 168 & 45 & 0.2679 \\
\hline 1993 & 157 & 35 & 0.2229 & 342 & 63 & 0.1842 & 168 & 40 & 0.2381 \\
\hline 1994 & 157 & 30 & 0.1911 & 342 & 52 & 0.1521 & 168 & 31 & 0.1845 \\
\hline
\end{tabular}

Table 6 Number of Best Practice and Its Proportions by Administration (1980-1994)

\begin{tabular}{|c|c|c|c|c|c|c|c|c|c|c|c|c|}
\hline \multirow[t]{2}{*}{ Year } & \multicolumn{3}{|c|}{ Ministry } & \multicolumn{3}{|c|}{ Province } & \multicolumn{3}{|c|}{ Region } & \multicolumn{3}{|c|}{ County } \\
\hline & Total & Best & Share & Total & Best & Share & Total & Best & Share & Total & Best & Share \\
\hline 1980 & 66 & 4 & 0.06 & 76 & 5 & 0.07 & 546 & 75 & 0.14 & 69 & 8 & 0.12 \\
\hline 1981 & 66 & 4 & 0.06 & 76 & 7 & 0.09 & 546 & 90 & 0.16 & 69 & 12 & 0.17 \\
\hline 1982 & 66 & 6 & 0.09 & 76 & 8 & 0.11 & 546 & 94 & 0.17 & 69 & 11 & 0.16 \\
\hline 1983 & 66 & 5 & 0.08 & 76 & 6 & 0.08 & 546 & 86 & 0.16 & 69 & 11 & 0.16 \\
\hline 1984 & 66 & 3 & 0.05 & 76 & 6 & 0.08 & 546 & 99 & 0.18 & 69 & 10 & 0.14 \\
\hline 1985 & 66 & 5 & 0.08 & 76 & 7 & 0.09 & 546 & 102 & 0.19 & 69 & 10 & 0.14 \\
\hline 1986 & 66 & 5 & 0.08 & 76 & 9 & 0.12 & 546 & 107 & 0.20 & 69 & 16 & 0.23 \\
\hline 1987 & 66 & 4 & 0.06 & 76 & 6 & 0.08 & 546 & 94 & 0.17 & 69 & 14 & 0.20 \\
\hline 1988 & 66 & 5 & 0.08 & 76 & 6 & 0.08 & 546 & 101 & 0.18 & 69 & 15 & 0.22 \\
\hline 1989 & 66 & 5 & 0.08 & 76 & 11 & 0.14 & 546 & 103 & 0.19 & 69 & 20 & 0.29 \\
\hline 1990 & 58 & 11 & 0.19 & 75 & 18 & 0.24 & 493 & 139 & 0.28 & 49 & 13 & 0.27 \\
\hline 1991 & 58 & 9 & 0.16 & 75 & 16 & 0.21 & 493 & 112 & 0.23 & 49 & 5 & 0.10 \\
\hline 1992 & 58 & 10 & 0.17 & 75 & 19 & 0.25 & 493 & 124 & 0.25 & 49 & 6 & 0.12 \\
\hline 1993 & 58 & 8 & 0.14 & 75 & 18 & 0.24 & 493 & 109 & 0.22 & 49 & 6 & 0.12 \\
\hline 1994 & 58 & 5 & 0.09 & 75 & 11 & 0.15 & 493 & 95 & 0.19 & 49 & 4 & 0.08 \\
\hline
\end{tabular}

Table 7 Number of Best Practice and Its Proportions by Province (1980-1994)

\begin{tabular}{|c|c|c|c|c|c|c|c|c|c|c|c|c|}
\hline \multirow[t]{2}{*}{ Year } & \multicolumn{3}{|c|}{ Jiangsu } & \multicolumn{3}{|c|}{ Jilin } & \multicolumn{3}{|c|}{ Shanxi } & \multicolumn{3}{|c|}{ Sichun } \\
\hline & Total & Best & Share & Total & Best & Share & Total & Best & Share & Total & Best & Share \\
\hline 1980 & 212 & 38 & 0.18 & 157 & 13 & 0.08 & 196 & 15 & 0.08 & 204 & 28 & 0.14 \\
\hline 1981 & 212 & 45 & 0.21 & 157 & 21 & 0.13 & 196 & 18 & 0.09 & 204 & 32 & 0.16 \\
\hline 1982 & 212 & 49 & 0.23 & 157 & 19 & 0.12 & 196 & 20 & 0.10 & 204 & 32 & 0.16 \\
\hline 1983 & 212 & 39 & 0.18 & 157 & 20 & 0.13 & 196 & 19 & 0.10 & 204 & 32 & 0.16 \\
\hline 1984 & 212 & 42 & 0.20 & 157 & 19 & 0.12 & 196 & 24 & 0.12 & 204 & 36 & 0.18 \\
\hline 1985 & 212 & 47 & 0.22 & 157 & 25 & 0.16 & 196 & 22 & 0.11 & 204 & 34 & 0.17 \\
\hline 1986 & 212 & 56 & 0.26 & 157 & 25 & 0.16 & 196 & 25 & 0.13 & 204 & 34 & 0.17 \\
\hline 1987 & 212 & 46 & 0.22 & 157 & 23 & 0.15 & 196 & 26 & 0.13 & 204 & 26 & 0.13 \\
\hline 1988 & 212 & 46 & 0.22 & 157 & 24 & 0.15 & 196 & 26 & 0.13 & 204 & 34 & 0.17 \\
\hline 1989 & 212 & 51 & 0.24 & 157 & 31 & 0.20 & 196 & 29 & 0.15 & 204 & 32 & 0.16 \\
\hline 1990 & 209 & 74 & 0.35 & 144 & 36 & 0.25 & 139 & 32 & 0.23 & 189 & 41 & 0.22 \\
\hline 1991 & 209 & 57 & 0.27 & 144 & 28 & 0.19 & 139 & 25 & 0.18 & 189 & 34 & 0.18 \\
\hline 1992 & 209 & 64 & 0.31 & 144 & 29 & 0.20 & 139 & 29 & 0.21 & 189 & 39 & 0.21 \\
\hline 1993 & 209 & 60 & 0.29 & 144 & 23 & 0.16 & 139 & 26 & 0.19 & 189 & 33 & 0.17 \\
\hline 1994 & 209 & 61 & 0.29 & 144 & 20 & 0.14 & 139 & 17 & 0.12 & 189 & 18 & 0.10 \\
\hline
\end{tabular}


Table 8 Proportion of High School Graduates or above in Total Employment by Scale and Proportion of Flexible Wage in Total Salary by Scale (1980-1994)

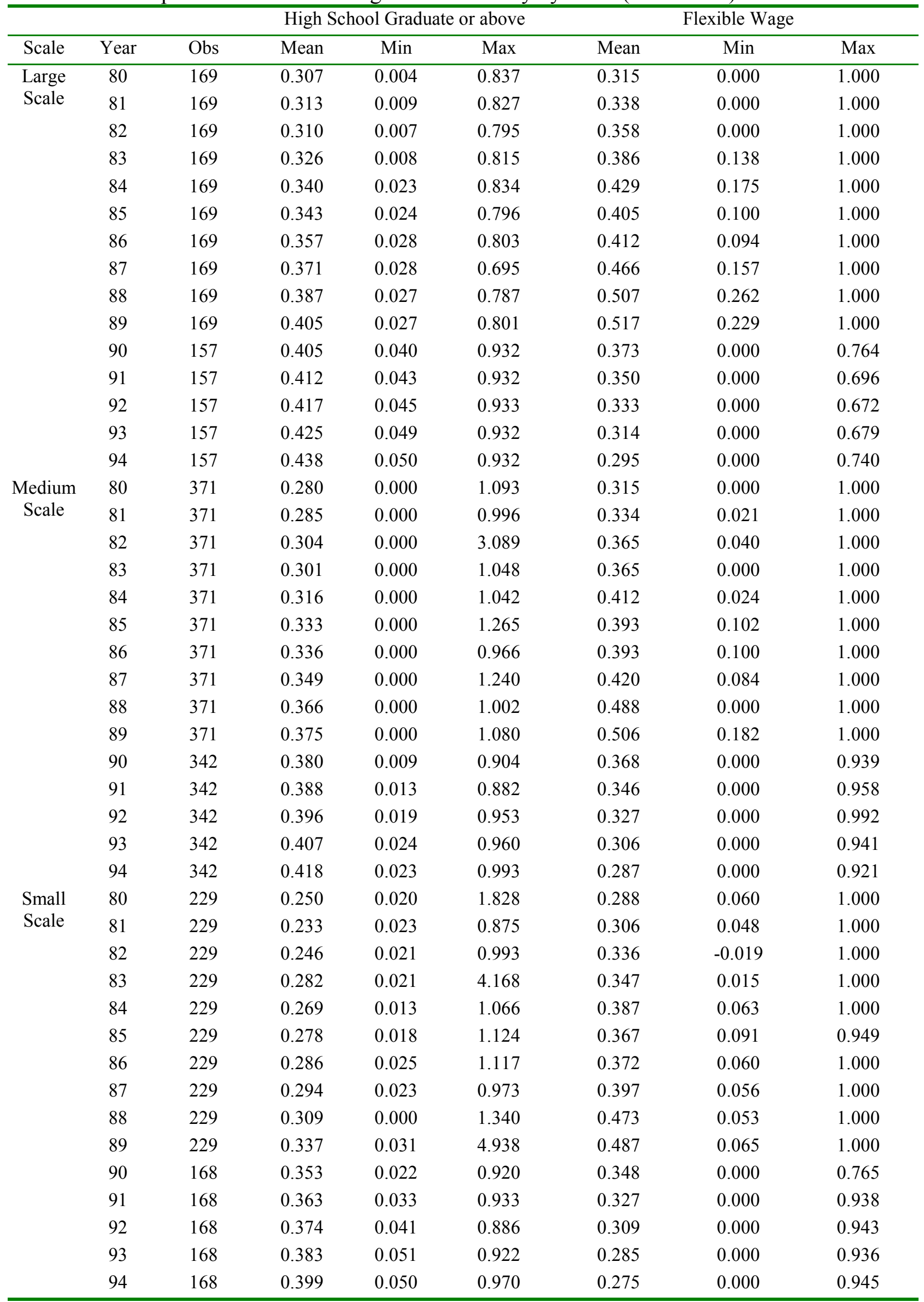


Table 9 Proportion of High School Graduates or above in Total Employment and

Proportion of Flexible Wage in Total Salary by Efficiency Interval (1980-1994)

\begin{tabular}{|c|c|c|c|c|c|c|c|c|}
\hline & & & \multicolumn{3}{|c|}{ High School Graduate or above } & \multicolumn{3}{|c|}{ Flexible Wage } \\
\hline Scale & Year & Obs & Mean & Min & Max & Mean & Min & Max \\
\hline \multirow{15}{*}{$\begin{array}{c}\text { Best } \\
\text { Practice }\end{array}$} & 80 & 94 & 0.242 & 0.020 & 0.712 & 0.290 & 0.058 & 0.603 \\
\hline & 81 & 116 & 0.247 & 0.020 & 0.815 & 0.315 & 0.031 & 0.914 \\
\hline & 82 & 120 & 0.296 & 0.018 & 0.887 & 0.351 & 0.006 & 0.975 \\
\hline & 83 & 110 & 0.312 & 0.021 & 0.894 & 0.369 & 0.098 & 1.000 \\
\hline & 84 & 121 & 0.314 & 0.000 & 0.910 & 0.413 & 0.131 & 1.000 \\
\hline & 85 & 128 & 0.333 & 0.018 & 0.907 & 0.394 & 0.167 & 1.000 \\
\hline & 86 & 140 & 0.336 & 0.027 & 0.881 & 0.393 & 0.083 & 1.000 \\
\hline & 87 & 121 & 0.328 & 0.058 & 0.689 & 0.444 & 0.079 & 1.000 \\
\hline & 88 & 130 & 0.363 & 0.000 & 0.812 & 0.487 & 0.053 & 1.000 \\
\hline & 89 & 143 & 0.366 & 0.000 & 0.801 & 0.498 & 0.065 & 1.000 \\
\hline & 90 & 179 & 0.367 & 0.022 & 0.932 & 0.380 & 0.010 & 0.939 \\
\hline & 91 & 141 & 0.376 & 0.033 & 0.932 & 0.374 & 0.035 & 0.958 \\
\hline & 92 & 157 & 0.370 & 0.037 & 0.933 & 0.342 & 0.033 & 0.992 \\
\hline & 93 & 138 & 0.395 & 0.051 & 0.932 & 0.321 & 0.000 & 0.936 \\
\hline & 94 & 113 & 0.393 & 0.072 & 0.970 & 0.287 & 0.000 & 0.639 \\
\hline \multirow[t]{15}{*}{$0.5-0.99$} & 80 & 234 & 0.268 & 0.000 & 1.000 & 0.310 & 0.000 & 1.000 \\
\hline & 81 & 267 & 0.287 & 0.000 & 0.995 & 0.331 & 0.000 & 0.990 \\
\hline & 82 & 310 & 0.278 & 0.000 & 0.993 & 0.367 & 0.040 & 1.000 \\
\hline & 83 & 275 & 0.296 & 0.000 & 1.048 & 0.356 & 0.075 & 1.000 \\
\hline & 84 & 307 & 0.310 & 0.000 & 0.972 & 0.411 & 0.024 & 1.000 \\
\hline & 85 & 298 & 0.317 & 0.000 & 1.265 & 0.389 & 0.098 & 1.000 \\
\hline & 86 & 281 & 0.320 & 0.000 & 0.940 & 0.393 & 0.060 & 1.000 \\
\hline & 87 & 279 & 0.343 & 0.000 & 1.240 & 0.423 & 0.071 & 1.000 \\
\hline & 88 & 301 & 0.356 & 0.000 & 1.340 & 0.490 & 0.115 & 1.000 \\
\hline & 89 & 275 & 0.388 & 0.000 & 4.938 & 0.494 & 0.131 & 1.000 \\
\hline & 90 & 342 & 0.374 & 0.009 & 0.925 & 0.360 & 0.000 & 0.932 \\
\hline & 91 & 351 & 0.390 & 0.013 & 0.933 & 0.336 & 0.000 & 0.908 \\
\hline & 92 & 331 & 0.398 & 0.019 & 0.953 & 0.314 & 0.000 & 0.806 \\
\hline & 93 & 266 & 0.424 & 0.024 & 0.960 & 0.294 & 0.000 & 0.941 \\
\hline & 94 & 316 & 0.420 & 0.023 & 0.993 & 0.284 & 0.000 & 0.945 \\
\hline \multirow[t]{15}{*}{$0.0-0.49$} & 80 & 112 & 0.268 & 0.000 & 0.871 & 0.301 & 0.000 & 1.000 \\
\hline & 81 & 155 & 0.258 & 0.000 & 0.875 & 0.312 & 0.154 & 1.000 \\
\hline & 82 & 133 & 0.259 & 0.000 & 0.880 & 0.337 & 0.000 & 1.000 \\
\hline & 83 & 186 & 0.296 & 0.000 & 4.168 & 0.381 & 0.071 & 1.000 \\
\hline & 84 & 169 & 0.275 & 0.000 & 1.018 & 0.411 & 0.063 & 1.000 \\
\hline & 85 & 179 & 0.295 & 0.000 & 1.025 & 0.376 & 0.091 & 1.000 \\
\hline & 86 & 190 & 0.309 & 0.000 & 0.893 & 0.374 & 0.121 & 1.000 \\
\hline & 87 & 213 & 0.322 & 0.000 & 0.898 & 0.406 & 0.056 & 1.000 \\
\hline & 88 & 178 & 0.325 & 0.000 & 0.884 & 0.475 & 0.000 & 1.000 \\
\hline & 89 & 198 & 0.332 & 0.000 & 0.918 & 0.506 & 0.183 & 1.000 \\
\hline & 90 & 50 & 0.377 & 0.025 & 0.904 & 0.313 & 0.000 & 0.893 \\
\hline & 91 & 83 & 0.350 & 0.026 & 0.877 & 0.298 & 0.000 & 0.951 \\
\hline & 92 & 84 & 0.383 & 0.051 & 0.907 & 0.313 & 0.000 & 0.942 \\
\hline & 93 & 170 & 0.358 & 0.071 & 0.929 & 0.293 & 0.000 & 0.870 \\
\hline & 94 & 146 & 0.402 & 0.050 & 0.871 & 0.281 & 0.000 & 0.739 \\
\hline
\end{tabular}


Table 10 Determinants of Technical Efficiency

\begin{tabular}{|c|c|c|c|c|c|c|}
\hline \multirow[b]{3}{*}{ Variable } & \multicolumn{4}{|c|}{ Dependent variable E3 } & \multicolumn{2}{|c|}{ Dependent variable E3 ${ }^{*}$} \\
\hline & Tobit model & & Tobit model & andom effects) & Probit model & \\
\hline & Coefficient & P-value & Coefficient & P-value & Coefficient & P-value \\
\hline Constant & 0.6640 & 0.0000 & 0.5612 & 0 & -1.3385 & 0 \\
\hline AGE & 0.0010 & 0.0001 & 0.000892 & 0.0212 & 0.0026 & 0.3364 \\
\hline WP & 0.1161 & 0.0000 & 0.0666 & 0 & 0.6538 & 0.0025 \\
\hline ED & 0.1004 & 0.0001 & 0.0886 & 0 & 0.6716 & 0.0081 \\
\hline KG & -0.0002 & 0.7260 & 0.00005 & 0.9612 & -0.0029 & 0.4546 \\
\hline PROV1 & 0.1299 & 0.0000 & 0.112654 & 0 & 0.8138 & 0 \\
\hline PROV2 & -0.0304 & 0.0026 & -0.0139 & 0.3053 & -0.1666 & 0.1025 \\
\hline PROV3 & -0.0319 & 0.0013 & 0.00211 & 0.8704 & -0.0338 & 0.7453 \\
\hline S1 & 0.0085 & 0.4369 & -0.00347 & 0.7508 & 0.2435 & 0.0172 \\
\hline S2 & -0.0270 & 0.0012 & -0.0382 & 0 & -0.2379 & 0.003 \\
\hline ADM1 & -0.0914 & 0.0000 & -0.0169 & 0.4272 & -0.6254 & 0.0009 \\
\hline ADM2 & -0.0431 & 0.0100 & 0.0547 & 0.0015 & -0.3313 & 0.0457 \\
\hline ADM3 & -0.0190 & 0.1419 & 0.0469 & 0.0006 & -0.1483 & 0.2531 \\
\hline Y81 & -0.0130 & 0.5564 & -0.0127 & 0.4266 & 0.2498 & 0.256 \\
\hline Y82 & 0.0104 & 0.6341 & 0.00941 & 0.5963 & 0.1914 & 0.3811 \\
\hline Y83 & -0.0614 & 0.0043 & -0.0572 & 0 & -0.0332 & 0.8805 \\
\hline Y84 & -0.0245 & 0.2518 & -0.0167 & 0.3184 & -0.1219 & 0.5789 \\
\hline Y85 & -0.0293 & 0.1630 & -0.0251 & 0.1338 & 0.0297 & 0.889 \\
\hline Y86 & -0.0430 & 0.0408 & -0.0383 & 0.0288 & 0.0698 & 0.7421 \\
\hline Y87 & -0.0838 & 0.0001 & -0.0705 & 0 & -0.2380 & 0.2731 \\
\hline Y88 & -0.0588 & 0.0057 & -0.0508 & 0.0056 & 0.0001 & 0.9996 \\
\hline Y89 & -0.0651 & 0.0022 & -0.0545 & 0.0003 & 0.0013 & 0.9951 \\
\hline Y90 & 0.1301 & 0.0000 & 0.100087 & 0 & 0.7822 & 0.0001 \\
\hline Y91 & 0.0777 & 0.0002 & 0.0629 & 0 & 0.3790 & 0.064 \\
\hline Y92 & 0.0881 & 0.0000 & 0.0661 & 0.0001 & 0.5721 & 0.0048 \\
\hline Y93 & -0.0259 & 0.2063 & -0.0342 & 0.0107 & 0.3755 & 0.0673 \\
\hline Y94 & -0.0095 & 0.6438 & -0.0118 & 0.4399 & 0.0701 & 0.7379 \\
\hline sigma (v) & & & 0.166866 & 0 & & \\
\hline $\operatorname{sigma}(u)$ & & & 0.13228 & 0 & & \\
\hline
\end{tabular}

(This table is subject to an error with education variable between 1990-94, but Tables 11 and 12 used the corrected one. However, this error shall not dramatically change the conclusion according to our experience.)

AGE - Age of the enterprise; WP - Flexible wage; ED - Education; KG - Capacity utilization; PROV - Province. 1, Jiangsu; 2, Jilin; 3, Shanxi; and 4, Sichuan.

$\mathrm{S}$ - Scale of the enterprise. 1, large; 2, medium; and 3, small.

ADM - Administration level. 1, central and ministry; 2, provincial; 3, region; 4, county. 
Table 11 Determinants of Productivity Growth, Efficiency Change, and Technical Progress

\begin{tabular}{|c|c|c|c|c|c|c|}
\hline \multirow[b]{3}{*}{ Variable } & \multirow{2}{*}{\multicolumn{2}{|c|}{$\begin{array}{c}\text { Productivity Growth } \\
\text { OLS method }\end{array}$}} & \multirow{2}{*}{\multicolumn{2}{|c|}{$\begin{array}{c}\text { Efficiency Change } \\
\text { OLS method }\end{array}$}} & \multirow{2}{*}{\multicolumn{2}{|c|}{$\begin{array}{c}\text { Technical Progress } \\
\text { Tobit model }\end{array}$}} \\
\hline & & & & & & \\
\hline & Coefficient & P-value & Coefficient & P-value & Coefficient & $\mathrm{P}$-value \\
\hline Constant & 1.0134 & 0.0001 & 0.9480 & 0.0001 & -0.2401 & 0.4536 \\
\hline DWP & 0.1145 & 0.0059 & 0.0829 & 0.0142 & 0.2965 & 0.3957 \\
\hline DED & 0.2466 & 0.0024 & 0.2407 & 0.0003 & 0.6478 & 0.1768 \\
\hline DKG & -0.0004 & 0.7509 & -0.0002 & 0.8192 & -0.00583 & 0.8318 \\
\hline PROV1 & 0.0311 & 0.0095 & 0.0237 & 0.015 & 0.2551 & 0.0254 \\
\hline PROV2 & 0.0155 & 0.2575 & 0.0110 & 0.3208 & 0.0618 & 0.6338 \\
\hline PROV3 & 0.0325 & 0.0156 & 0.0170 & 0.1202 & 0.0218 & 0.8621 \\
\hline $\mathrm{S} 1$ & 0.0086 & 0.55 & 0.0101 & 0.3898 & 0.2547 & 0.0622 \\
\hline $\mathrm{S} 2$ & -0.0112 & 0.3123 & -0.0070 & 0.4387 & 0.1361 & 0.1782 \\
\hline ADM1 & -0.0037 & 0.8796 & -0.0072 & 0.718 & -0.1159 & 0.6216 \\
\hline ADM2 & 0.0067 & 0.7687 & 0.0013 & 0.9434 & -0.0717 & 0.7334 \\
\hline ADM3 & -0.0009 & 0.9606 & -0.0065 & 0.646 & 0.0193 & 0.9024 \\
\hline Y82 & 0.0688 & 0.016 & 0.0929 & 0.0001 & 0.9136 & 0.0001 \\
\hline Y83 & 0.1162 & 0.0001 & 0.0077 & 0.7373 & 2.6449 & 0.0001 \\
\hline Y84 & 0.0808 & 0.0036 & 0.0980 & 0.0001 & 1.5325 & 0.0001 \\
\hline Y85 & 0.0421 & 0.1261 & 0.0653 & 0.0035 & 2.2018 & 0.0001 \\
\hline Y86 & 0.0471 & 0.0817 & 0.0824 & 0.0002 & 2.2525 & 0.0001 \\
\hline Y87 & 0.0707 & 0.0088 & 0.0572 & 0.0091 & 2.1054 & 0.0001 \\
\hline Y88 & 0.0866 & 0.0012 & 0.0929 & 0.0001 & 2.0409 & 0.0001 \\
\hline Y89 & 0.0088 & 0.7403 & 0.0400 & 0.0653 & 1.4696 & 0.0001 \\
\hline Y90 & 0.1535 & 0.0001 & 0.1700 & 0.0001 & 0.0602 & 0.734 \\
\hline Y91 & -0.0445 & 0.0789 & -0.0093 & 0.6507 & -0.1901 & 0.2207 \\
\hline Y92 & 0.0370 & 0.1429 & 0.0530 & 0.0099 & 1.3859 & 0.0001 \\
\hline Y93 & 0.1080 & 0.0001 & -0.0461 & 0.025 & 3.7264 & 0.0001 \\
\hline Y94 & 0.0941 & 0.0002 & 0.1074 & 0.0001 & 2.0832 & 0.0001 \\
\hline
\end{tabular}


Table 12 Probability of Productivity Growth, Efficiency Change, and Technical progress

\begin{tabular}{|c|c|c|c|c|c|c|}
\hline \multicolumn{7}{|c|}{ Logit Model Results } \\
\hline \multirow[b]{2}{*}{ Variable } & \multicolumn{2}{|c|}{ Dependent variable $\mathrm{M}_{\mathrm{o}}^{*}$} & \multicolumn{2}{|c|}{ Dependent variable $\mathrm{MC}^{*}$} & \multicolumn{2}{|c|}{ Dependent variable $\mathrm{MF}^{*}$} \\
\hline & Coefficient & P-value & Coefficient & P-value & Coefficient & P-value \\
\hline Constant & -0.4411 & 0.0782 & -1.0876 & 0.0001 & -0.2401 & 0.4536 \\
\hline DWP & 0.7827 & 0.0017 & 0.5769 & 0.0263 & 0.2965 & 0.3957 \\
\hline DED & 0.8078 & 0.0595 & 0.5205 & 0.2468 & 0.6478 & 0.1768 \\
\hline $\mathrm{DKG}$ & -0.0196 & 0.6363 & -0.0207 & 0.4761 & -0.00583 & 0.8318 \\
\hline PROV1 & 0.3684 & 0.0001 & 0.0546 & 0.4832 & 0.2551 & 0.0254 \\
\hline PROV2 & 0.0887 & 0.286 & 0.0169 & 0.8494 & 0.0618 & 0.6338 \\
\hline PROV3 & -0.00721 & 0.9294 & 0.0598 & 0.4863 & 0.0218 & 0.8621 \\
\hline $\mathrm{S} 1$ & 0.1837 & 0.0377 & -0.0825 & 0.3781 & 0.2547 & 0.0622 \\
\hline $\mathrm{S} 2$ & 0.0149 & 0.8241 & 0.00216 & 0.976 & 0.1361 & 0.1782 \\
\hline ADM1 & 0.0515 & 0.7316 & 0.1174 & 0.4526 & -0.1159 & 0.6216 \\
\hline ADM2 & 0.1704 & 0.2188 & -0.0179 & 0.9026 & -0.0717 & 0.7334 \\
\hline ADM3 & 0.0294 & 0.78 & -0.1126 & 0.3145 & 0.0193 & 0.9024 \\
\hline Y82 & 0.4356 & 0.0078 & 0.1487 & 0.4109 & 0.9136 & 0.0001 \\
\hline Y83 & 1.2646 & 0.0001 & 0.4794 & 0.006 & 2.6449 & 0.0001 \\
\hline Y84 & 0.8918 & 0.0001 & 0.4028 & 0.0195 & 1.5325 & 0.0001 \\
\hline Y85 & 0.664 & 0.0001 & 0.1515 & 0.3859 & 2.2018 & 0.0001 \\
\hline Y86 & 0.4549 & 0.0034 & 0.0682 & 0.6943 & 2.2525 & 0.0001 \\
\hline Y87 & 0.8919 & 0.0001 & 0.3154 & 0.0627 & 2.1054 & 0.0001 \\
\hline Y88 & 0.7183 & 0.0001 & 0.4697 & 0.0049 & 2.0409 & 0.0001 \\
\hline Y89 & 0.3666 & 0.0168 & 0.1418 & 0.4042 & 1.4696 & 0.0001 \\
\hline Y90 & 0.3221 & 0.0432 & 0.6062 & 0.0004 & 0.0602 & 0.734 \\
\hline Y91 & -0.1779 & 0.2221 & -0.4952 & 0.0038 & -0.1901 & 0.2207 \\
\hline Y92 & 0.6717 & 0.0001 & -0.039 & 0.8109 & 1.3859 & 0.0001 \\
\hline Y93 & 1.3197 & 0.0001 & -0.3813 & 0.0238 & 3.7264 & 0.0001 \\
\hline Y94 & 1.2064 & 0.0001 & 0.4966 & 0.0017 & 2.0832 & 0.0001 \\
\hline
\end{tabular}


${ }^{1}$ The SOE share in China's total industrial output has declined from 77.6 percent in 1978 to 28.8 percent in 1996. However, in 1996 SOE's still employed 57.4 percent of urban workers and possessed 52.2 percent of total investment in industrial fixed assets (Lin, et. al, 1998).

${ }^{2}$ Once the powerhouse behind the economy's growth and employment, the dynamism of China's 1.5 million collectively owned enterprises has waned. After generating some 17 million jobs in 1993, they created just 1.4 million in 1994 and 1995, while private and individually owned enterprises created 6.6 million new jobs (World Bank, 1997).

${ }^{3}$ A new industrial policy announced on March 25, 1994 emphasised the development of "pillar" industries. Five pillar industries have been designated by the government: machinery, electronics, petrochemicals, automobiles, and construction. These industries were chosen because they are expected to face a high income elasticity of demand, enjoy substantial economies of scale, result in significant backward and forward production linkages, possess potential for high productivity growth, and reflect China's comparative advantage. The hope is that they will eventually account for 5 percent of GDP (or 8 percent of industrial output), increase their share in international markets, reach international quality standards quickly, and become profitable (World Bank, 1997, page 39).

${ }^{4}$ Widely cited studies using aggregate time series data include: Chen et. al (1988), Jefferson et. al (1994 and 1996), Jefferson and Singh (1993), Rawski (1986), Woo et. al (1994), and Wu (1993); while Parker (1997), Li (1997), and Wu (1996) are examples of studies in which enterprise data were used.

${ }^{5}$ Since we assume constant returns to scale, the deference between their output increasing and input saving efficiency disappears.

${ }^{6}$ The evidence is that if one divides the output in current price (in 1980 or 1990) by the output in fixed price (1980, or 1990 price), most results give values other than unity.

${ }^{7}$ The proportion of high school graduates or above in total employment and the proportion of flexible wage in total salary is shown by scale and year in Table 8 and by efficiency interval and year in Table 9.

${ }^{8}$ Results in Table 10 were produced using a recent version of LIMDEP. Tables 11 and 12 were obtained using SAS. Probit models were estimated by the Proc Logistic procedure. 